\title{
Recommitting to the elimination of tobacco use
}

\section{Joanna E Cohen}

World No Tobacco Day (31 May) provides an opportunity for nations and the global community to focus attention on the immense yet completely preventable harm caused by tobacco products, and to commit to specific actions that can better address this devastating epidemic.

The 2013 theme for World No Tobacco Day (WNTD) is banning tobacco advertising, promotion and sponsorship (TAPS). Allowing these deadly products to be advertised and promoted in diverse settings and through a variety of channels clearly undermines our health promotion messages that these products are harmful and should not be used. This contradiction also hands doubt to anyone looking for it: tobacco products really can't be all that bad.

In many countries, the point-of-sale (POS) is an important venue where advertising and promotion take place. In this issue of the journal, Scheffels and Lavik assess retailers' compliance and consumers' perceptions of Norway's recent ban on the display of tobacco at the POS. ${ }^{1}$ They find, as others have previously, that there is very high retailer compliance with a total display ban. Although more studies are needed on the behavioural impacts of tobacco display bans, reducing the visibility of these products can be expected to contribute to the denormalisation of tobacco industry products and ultimately increase smoking cessation and reduce smoking initiation and relapse.

The article by Coady et $a^{2}$ focuses on another potential requirement at the POS: the posting of graphic tobacco health warning signs by retailers in New York City. Even though New York City never enforced the signage requirement because the regulation was challenged by tobacco manufacturers, retailers and trade associations, and was eventually overturned, signage was distributed and retailers could post the signs if they so chose. The authors report that knowledge of tobacco-caused health risks increased and thoughts about quitting smoking were higher among smokers following signage distribution. While further evaluation is required to determine the impacts of POS tobacco

Correspondence to Dr Joanna E Cohen, Institute for Global Tobacco Control, Department of Health, Behavior and Society, Johns Hopkins Bloomberg School of Public Health, 2213 McElderry Street, 4th Floor, Baltimore, MD 21205, USA; jocohen@jhsph.edu health warning signage on tobacco use, it is important that the public continues to be informed and educated about the reasons for implementing tobacco control policy interventions.

At the POS and beyond, the package itself is an important vehicle for advertising tobacco brands. Health warning labels on tobacco packages not only communicate important health information and represent a first step toward informed consent on the part of users, but large labels also take away brand advertising real estate. Partos et al in this issue report that recent quitters who say that warning labels help them a lot to stay quit are less likely to relapse. Thrasher et $a l^{4}$ find that pictorial health warning labels linked to a media campaign in Mexico were associated with greater knowledge and quit-related psychosocial and behavioural responses. We need to continue to study the synergistic effects of multiple tobacco control policies so that we can more effectively and efficiently implement them moving forward.

Whether referring to TAPS, smoke-free public places, tobacco prices, warning messages about the harms of tobacco products, or reduced availability of tobacco products, it can be hypothesised that the 'dose' of tobacco control needs to continue to increase in order to maintain a proportional decline in smoking prevalence. Currie et a ${ }^{5}$ use a popular dynamic simulation model to show that despite achieving important reductions in smoking prevalence in Ireland from tobacco control policies implemented between 1998 and 2010, a further reduction could be achieved if Ireland's policies became fully compliant with the FCTC. The SimSmoke simulation model could be used in the future to investigate by how much and how frequently the dose of tobacco control needs to be increased in order to achieve continued reductions in smoking prevalence over time. Max and colleagues demonstrate using data from the US state of California that when tobacco control funding remains stagnant, smoking prevalence and health care expenditures increase as the real dollar value of the funding erodes over time. ${ }^{6}$

Indeed, Edwards et al show, once again, that smokers in New Zealand are ahead of their policymakers in supporting stronger regulation of the tobacco industry. To significantly reduce the millions of preventable tobacco-caused deaths that we currently experience on an annual basis, countries need to become fully compliant with the FCTC without delay, and quickly go beyond the 'floor' that the FCTC provides to implement even stronger measures in an effort to begin to undo the decades of devastation resulting from the rampant advertising and promotion of tobacco products.

As smokers are urged toward cessation with increasing doses of tobacco control policies, we must ensure that we also provide smokers with the cessation supports that they need. Oh and colleagues in this issue report that the governmentsupported smoking cessation clinics in the Republic of Korea are indeed cost-effective. ${ }^{8}$

As we mark another WNTD, it is crucial that readers of this journal make every effort to speak with the media about this important public health issue. A recent study showed that tobacco cessation news coverage peaks significantly around WNTD, and that a doubling in cessation news coverage is associated with about a $50 \%$ increase in Internet smoking cessation queries. ${ }^{9}$ The more media coverage there is, the more likely people seek out information on quitting. Banning TAPS is an excellent way to support tobacco users in their quit attempts.

\section{Competing interests None.}

Provenance and peer review Not commissioned; internally peer reviewed.

Tobacco Control 2013;22:e1.

doi:10.1136/tobaccocontrol-2013-051154

\section{REFERENCES}

1. Scheffels J, Lavik R. Out of sight, out of mind? Removal of point-of-sale tobacco displays in Norway. Tob Control 2013;22:e37-e42.

2. Coady $\mathbf{M H}$, Chan CA, Auer K, et al. Awareness and impact of New York City's graphic point-of-sale tobacco health warning signs. Tob Control 2013;22:e51-e56.

3. Partos TR, Borland R, Yong HH, et al. Cigarette packet warning labels can prevent relapse: findings from the International Tobacco Control 4-Country policy evaluation cohort study. Tob Control 2013;22:e43-e50.

4. Thrasher JF, Murukutla N, Perez-Hernandez R, et al. Linking mass media campaigns to pictorial warning labels on cigarette packages: a cross-sectional study to evaluate effects among Mexican smokers. Tob Control 2013;22:e57-e65.

5. Currie LM, Blackman K, Clancy L, et al. The effect of tobacco control policies on smoking prevalence and smoking-attributable deaths in Ireland using the IrelandSS simulation model. Tob Control 2013;22:e25-e32.

6. Max W, Sung HY, Lightwood J. The impact of changes in tobacco control funding on healthcare expenditures in California, 2012-2016. Tob Control 2013;22:e10-e15.

7. Edwards R, Wilson N, Peace J, et al. Support for a tobacco endgame and increased regulation of the tobacco industry among New Zealand smokers: results from a national survey. Tob Control 2013;22:e86-e93.

8. Oh JK, Lim MK, Yun EH, et al. Cost and effectiveness of the nationwide government-supported smoking cessation clinics in the Republic of Korea. Tob Control 2013;22:e73-e77.

9. Ayers JW, Althouse BM, Allem JP, et al. A novel evaluation of World No Tobacco day in Latin America. J Med Internet Res 2012;14:e77. 